\title{
EFEITO DOS COMPOSTOS ORAGANOCALCOGÊNEOS (PhSe)2 E (p-Cl-PhSe)2 SOBRE A VIABILIDADE DO BIOFILME FORMADO POR Candida albicans
}

\author{
Marília Toledo Braga' \\ Isabela Bueno Rosseti ${ }^{2}$ \\ Maricilia Silva Costa ${ }^{3}$
}

Resumo: Os fungos do gênero Candida são capazes de produzir infecções superficiais ou sistêmicas em indivíduos com baixa resposta imunológica. Estes fungos promovem infecções a partir da sua capacidade de formar biofilmes. Os biofilmes formados por $C$. albicans são mais resistentes aos tratamentos antifúngicos convencionais. Portanto o objetivo deste trabalho foi avaliar e comparar o potencial antifúngico dos compostos organocalcogêneos ( $\mathrm{PhSe}) 2$ e ( $\mathrm{p}-\mathrm{Cl}-\mathrm{PhSe}) 2$ sobre os biofilmes de C. albicans. Suspensões de C. albicans foram incubadas para a formação do biofilme e estes foram tratados com os compostos organocalcogêneos por 24 horas. Os resultados obtidos demonstraram o potencial antifúngico de ambos compostos sobre o biofilme formado por C. albicans, inibindo a viabilidade do biofilme e reduzindo a quantidade de células planctônicas. Esses compostos apresentaram uma resposta terapêutica promissora, uma vez que as opções para tratamento de infecções fúngicas é limitado.

Palavras-chave: Candida albicans; Compostos organocalcogêneos; Biofilme.

\footnotetext{
${ }^{1}$ Laboratório de Bioquímica Aplicada a Engenharia Biomédica/UNIVAP, Brasil. E-mail: marilia.braga@live.com.

2 Laboratório de Bioquímica Aplicada a Engenharia Biomédica/UNIVAP, Brasil. E-mail: isabelabros@hotmail.com.

${ }^{3}$ Laboratório de Bioquímica Aplicada a Engenharia Biomédica/UNIVAP, Brasil. E-mail: mscosta@univap.br.
} 